\title{
NUTRICIÓN
}

\section{Evaluación del nivel de conocimiento sobre la lactancia materna exclusiva en alumnas de la Universidad Iberoamericana, Sede Central}

\author{
Liz Casco Bécker ${ }^{1}$, Luz Vera ${ }^{1}$
}

\begin{abstract}
Resumen
Introducción: La lactancia materna exclusiva es beneficiosa no solo para el binomio madre-hijo, sino también para la familia, el conocimiento de estos beneficios no parece ser suficiente como para que las madres prolonguen su duración y su buena práctica. Si bien es cierto las cifras sobre la lactancia materna han aumentado en nuestro país en los últimos años, pero aún sigue siendo un bajo porcentaje.
\end{abstract}

Objetivo: Determinar el nivel de conocimiento sobre la lactancia materna exclusiva en alumnas de la Universidad Iberoamericana sede central

Material y Método: Observacional descriptiva de corte transverso. Los datos serán recolectados a través de un cuestionario que posteriormente serán analizados. Computadora para registrar datos, Calculadoras, bolígrafos, borradores, libros, internet para recolectar información.

Resultados: La mayoría de la población encuestada está en conocimiento de que la lactancia materna exclusiva sin incluir otro tipo de alimento al bebé es apta hasta los 6 meses de edad, además la mayoría conoce lo que es el calostro y su función, en el mayor porcentaje hay conocimiento de la frecuencia de amamantamiento al bebé, además la población en estudio conoce que recién a partir de los 6 meses pueden ser incorporados otros alimentos además de la leche materna, casi el $80 \%$ de las encuestadas concluye que tienen conocimiento acerca de los beneficios que reúnen la lactancia materna exclusiva. Un punto muy importante en el hallazgo de los resultados es el de la incomodidad de ver a una mujer dando de mamar a los que el $98 \%$ de las encuestadas respondió que no les es incómodo. En cuanto al conocimiento sobre alguna ley que promocione la lactancia materna exclusiva el 70\% de las encuestadas dijo que en nuestro país si existe una ley para tal efecto.

Conclusiones: Podemos ver a través del presente trabajo de que las alumnas que han sido encuestadas poseen un conocimiento aceptable en cuanto refiere

\footnotetext{
1. Universidad Iberoamericana, Facultad de Ciencias de la Salud, Paraguay.

E-mail: nutriciontarde2020@gmail.com

DOI: $10.26885 /$ rcei.foro.2019.237
}

Trabajo publicado en acceso abierto bajo Licencia Creative Commons. 
Casco Bécker, L., et al. Evaluación del nivel de conocimiento sobre la lactancia materna

a lactancia materna exclusiva.

Palabras clave: lactancia, exclusiva, beneficios.

\section{REFERENCIAS}

OMS. (2016). Lactancia materna exclusiva. EE. UU. 2016. http://www.who.int/ nutrition/topics/exclusive_breastfeeding/es/

OMS. (2016). Lactancia materna. http://www.who.int/topics/breastfeeding/ es/ 